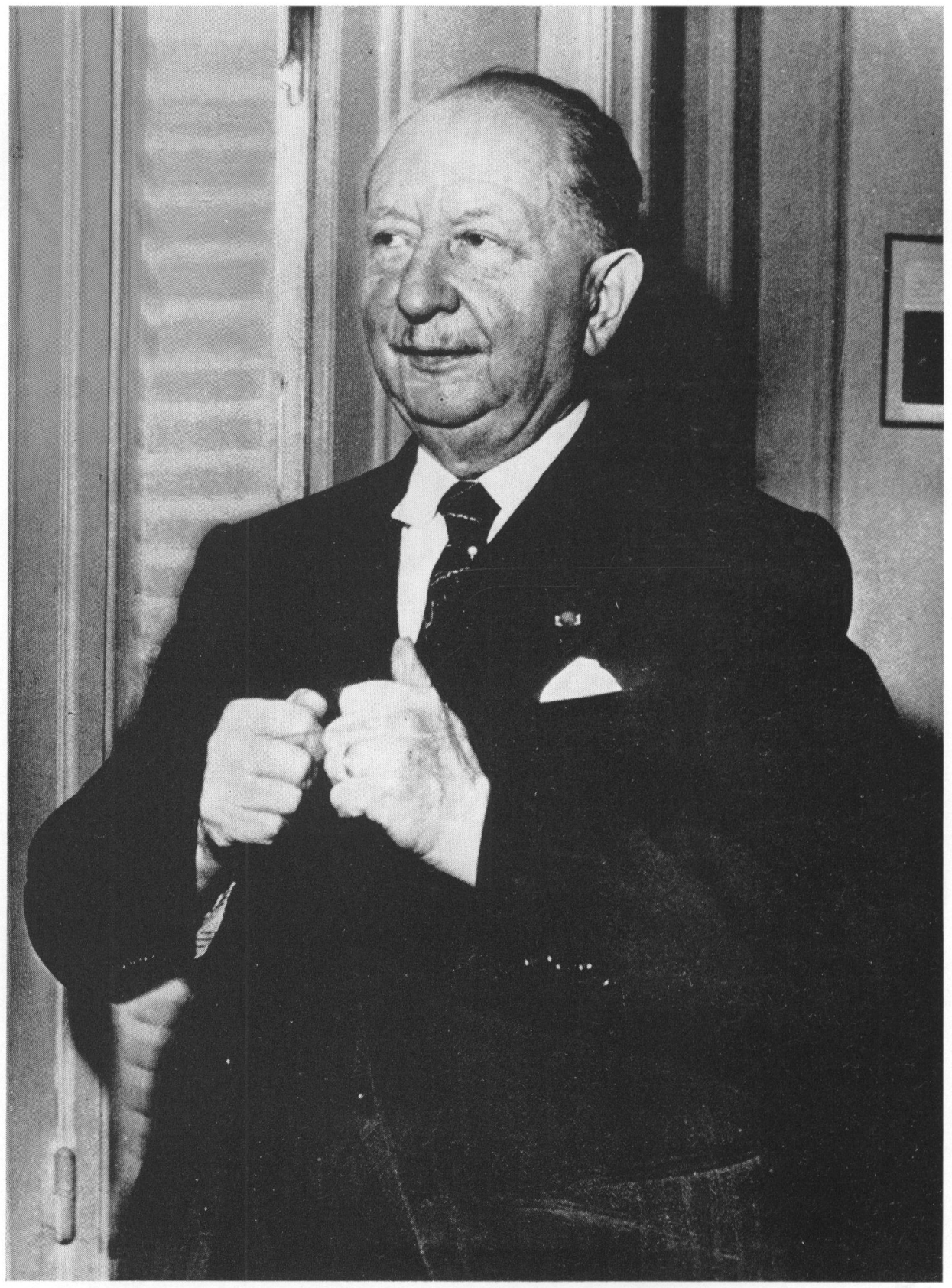

LUCIEN FEBVRE 


\section{Le dixième anniversaire de la mort de Lucien Febvre}

En ce dixième anniversaire de la mort de Lucien Febvre (27 septembre 1956), les Annales voudraient redire leur fidélité et leur admiration affectueuse à l'égard de leur fondateur. Avons-nous eu raison de nous obstiner d continuer son æuvre, d'essayer de maintenir vivante et efficace cette revue où il a, ainsi que Marc Bloch, mis hier le meilleur de lui-même? Rien n'est plus ardu et hasardeux que de prolonger une politique intellectuelle. Mais l'héritage de Marc Bloch et de Lucien Febvre n'est pas, pensons-nous, tel ou tel thème de leurs recherches et de leurs préoccupations. Il ne s'agit pas de réécrire, vaille que vaille, avec les corrections de détail et les mises à jour nécessaires, la Religion de Rabelais ou les Caractères Originaux. Continuer, ce n'est certainement pas répéter et si la vocation des Annales a été, dès les premiers jours, d'ouvrir le métier d'historien aux nouveautés et aux problématiques inédites, il nous faut continuer d tenir les portes ouvertes devant tous les courants nouveaux, même si quelquefois ils paraissent risqués et discutables.

André Piganiol, qui a collaboré aux Annales dès leur création, nous écrivait le 17 août 1966 : "Les Annales peuvent être fières de leur action. Dans le dernier numéro, sans chercher davantage, je trouve une excellente étude d'anthropologie archéologique, une bonne recherche sur la colonisation grecque. Les points de vue sont renouvelés, rien n'aurait plu davantage à Marc Bloch et à Lucien Febore. A cet égard, votre œuvre continue réellement leur action. "C'est ce dernier mot qui nous fait le plus de plaisir. Il nous paie de longs efforts patients.

Bien entendu les voies nouvelles obligent à des oublis. Nous parlons beaucoup moins de la géographie qu'hier. Les progrès de l'économie politique vont nous obliger demain d̀ changer encore notre fusil d'épaule. La sociologie reste l'obstacle essentiel, non le seul. Toutes les sciences de l'homme peuvent se présenter comme des sciences auxiliaires de l'histoire : ou celle-ci saisit l'occasion qui s'offre à elle de s'enrichir et de dominer cette masse d'idées et de faits nouveaux, ou elle rate cette opération vitale. De toute façon, elle court le risque d'être "cachée ", submergée par le torrent des sciences sociales. Conserver à l'histoire son rôle et sa significa- 


\section{A N NAIES}

tion au fur et à mesure que se déforme l'ensemble de l'acquis et de la recherche scientifiques, c'est l'ambition que nous ont dictée d'avance, nous semble-t-il, les promoteurs des Annales.

Il nous eût été agréable de rendre à Lucien Febvre un autre hommage. Nous aurions volontiers publié ses cours, ses lettres admirables. Ses cours ne sont jamais écrits de bout en bout et ne seraient publiables que si les phrases étaient complétées, remises d'aplomb. On hésite quand on connaît le soin méticuleux qu'il apportait à mettre un livre au point, ses exigences de forme. Pourtant c'est ce travail que fit hier Camille Jullian pour la gloire de Fustel de Coulanges. Quand aux lettres de Lucien Febore, nous espérons qu'un jour, avec les délais de rigueur, elles seront mises à la disposition des lecteurs.

Ces documents d'une extrême richesse aideront à mieux suivore, sinon sa pensée — là-dessus ses livres disent certes l'essentiel —, du moins son rôle qui fut aussi grand que sa générosité : ses lettres seules en donneraient la vraie mesure. Chaque génération a ses ravitailleurs en idées, ses "caissiers ", me disait un jour Hans Alban, collaborateur de Joliot-Curie. Langevin a été le caissier des physiciens de son époque, comme Diderot des philosophes de l'Encyclopédie. Lucien Febvre fut le "caissier " des historiens de son temps. Et ce rôle, il l'a tenu magnifiquement, avec élégance, bonheur et générosité, avec passion surtout, une passion contagieuse.

Fernand Braudel. 